\title{
Mixing and combustion modeling of hydrogen peroxide/kerosene shear-coaxial jet flame in lab-scale rocket engine
}

\author{
Sen $\mathrm{Li}^{\mathrm{a}}{ }^{\mathrm{a}}$, Yifei Ge ${ }^{\mathrm{b}}$, Xiaolin Wei ${ }^{\mathrm{a}}$, Teng $\mathrm{Li}^{\mathrm{a}}$ \\ a State Key Laboratory of High Temperature Gas Dynamics, Institute of Mechanics, Chinese Academy of Sciences, No. 15 Beisihuanxi Road, Beijing, 100190, China \\ b University of Chinese Academy of Sciences, Beijing 100190, China
}

\section{A R T I C L E I N F O}

\section{Article history:}

Received 11 June 2016

Received in revised form 2 July 2016

Accepted 17 July 2016

Available online 22 July 2016

\section{Keywords:}

$\mathrm{H}_{2} \mathrm{O}_{2}$

Kerosene

Shear-coaxial jet

Combustion

Plume

\begin{abstract}
A B S T R A C T
$\mathrm{H}_{2} \mathrm{O}_{2} /$ kerosene bipropellants are effective alternatives for toxic propellants currently in use. The complex $\mathrm{H}_{2} \mathrm{O}_{2}$ /kerosene turbulent flow and combustion chemical reaction are modeled, the atomization, evaporation and mixing are investigated, the characteristics of the complex chemical reaction path of kerosene at different stages in combustion chamber are analyzed, and the profiles of static pressure, temperature and Mach number of exhaust plume are provided. During the kerosene injection, the spray angle is $13^{\circ}$, the atomization and evaporation occur and complete simultaneously, the lasting time of atomization is about $1 \mathrm{~ms}$, and the maximal vaporization rate reaches $1.5 \times 10^{-6} \mathrm{~kg} / \mathrm{s}$. The combustion chamber can be divided into the following three zones: rapid high-temperature pyrolysis zone, oxidization zone and equilibrium flow zone. The initial excitation of kerosene reactions is crucial link, and the hydrogen abstraction reactions are the dominant reactions in the high pyrolysis. These peak values of static pressure, temperature, Mach number along plume axis almost evenly distribute, and the interval distances are about $32 \mathrm{~mm}$ along the centerline of axis.
\end{abstract}

(c) 2016 Elsevier Masson SAS. All rights reserved.

\section{Introduction}

Green and nontoxic hypergolic $\mathrm{H}_{2} \mathrm{O}_{2}$ / kerosene bipropellants are promising candidates as effective alternatives for toxic propellants currently in use [1]. Rocket-grade $\mathrm{H}_{2} \mathrm{O}_{2}$ (concentration $\alpha \geq 85 \%$ ) is decomposed into a high-temperature $(T \geq 1000 \mathrm{~K})$ and oxygenrich steam as it comes in contact with a catalyst medium. This leads to an automatic ignition with a liquid fuel in a bipropellant engine without a requirement for a separate ignition unit.

Previously, a test of $100 \mathrm{~N}$-thrust laboratory scale $\mathrm{H}_{2} \mathrm{O}_{2}$ / kerosene rocket engine was performed. Due to high-pressure and hightemperature environment in the combustion chamber, the processes of kerosene spray, atomization, vaporization, mixing and chemical reaction were very difficult to be diagnosed, and the combustion chamber pressure and the exhaust plume image were only monitored.

The process of $\mathrm{H}_{2} \mathrm{O}_{2}$ / kerosene combustion is very complex. Since the turbulence and the chemical reactions not only interact with each other but also with the spray processes [2], the presence of the liquid phase complicates the situation. An improved understanding of the physical and chemical processes occurring in

\footnotetext{
* Corresponding author.

E-mail address: lisen@imech.ac.cn (S. Li).
}

liquid rocket engines is required to ensure the stability, reliability, and efficiency of the engines.

In the study, in order to discover the complex process of $\mathrm{H}_{2} \mathrm{O}_{2} /$ kerosene combustion in rocket engine, based on the previous test, the complex gas-liquid turbulent flow and combustion chemical reaction are modeled, the atomization, evaporation and mixing are investigated, the characteristics of the complex chemical reaction path of kerosene are analyzed, and the profiles of static pressure, temperature and Mach number of exhaust plume are provided.

\section{Lab-scale rocket engine configurations and experimental conditions}

In the previous experiment, the rocket engine consists of silver screen catalyst bed, injector, combustion chamber and nozzle, as shown in Fig. 1. The length and inner diameter of combustion chamber are $100 \mathrm{~mm}$ and $25 \mathrm{~mm}$, respectively. The inner diameters of the nozzle throat and nozzle exit are $7.5 \mathrm{~mm}$ and $15 \mathrm{~mm}$, respectively. The above detailed configurations are mentioned in the following computing domain of combustion.

$\mathrm{H}_{2} \mathrm{O}_{2}$ and kerosene were pressurized with a regulated nitrogen gas manifold system. The propellants were controlled by a pneumatic actuator operated using a solenoid valve. $90 \% \mathrm{H}_{2} \mathrm{O}_{2}$ was decomposed into high-temperature mixture of water vapor and 


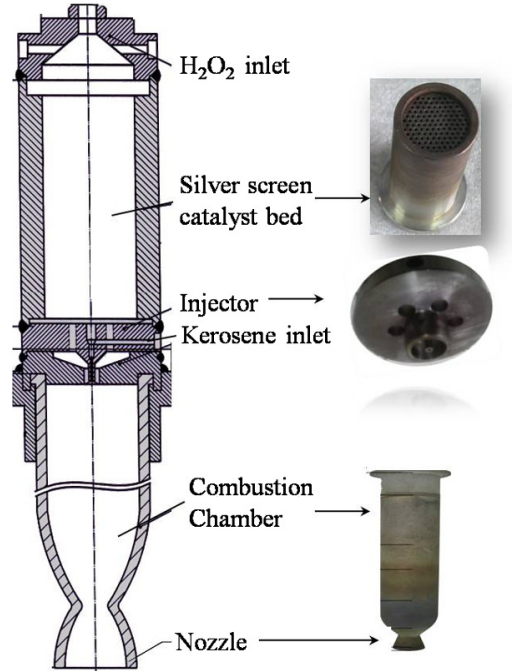

Fig. 1. Schematic of the experimental engine.

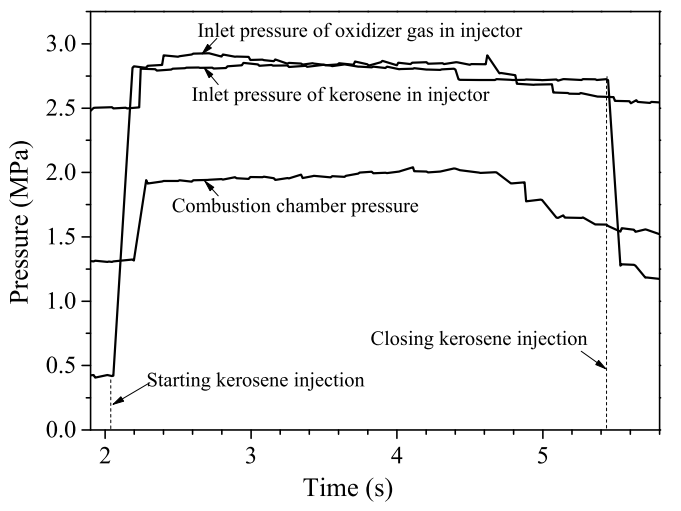

Fig. 2. Operating pressures of injector and combustion chamber in the experiment.

oxygen (mass concentration: $42.3 \% \mathrm{O}_{2}, 57.7 \% \mathrm{H}_{2} \mathrm{O} ; 1030 \mathrm{~K}$ ) when it passed through the silver screen catalyst bed, and the decomposed stream was used as oxidizer.

The operating pressures of injector and combustion chamber were measured in the experiment, as shown in Fig. 2. At the injector inlet, the operating pressures of kerosene and oxidizer are about $2.8 \mathrm{MPa}$, and mass flow rates of kerosene and oxidizer are $7 \mathrm{~g} / \mathrm{s}$ and $43 \mathrm{~g} / \mathrm{s}$, respectively. In the experiment, $\mathrm{H}_{2} \mathrm{O}_{2}$ was injected $2 \mathrm{~s}$ before kerosene was injected, and kerosene injection lasted for $3.5 \mathrm{~s}$. The combustion chamber pressure was measured, and it was about $2 \mathrm{MPa}$. Since the combustion residence time is less than $10 \mathrm{~ms}$ in combustion chamber, the heat transfer through the chamber wall can be ignored, and the wall is considered as adiabatic wall in the simulation.

In the experiment, China No. 3 aviation kerosene was employed, the measured mass fractions of various components were listed in Table 1 [3]. Guided by Dagaut's three-component surrogate [4], Fan et al. [5] given the surrogate fuel consisted by mole of $49 \% n$-decane, 44\% 1,3,5-trimethylcyclohexane, and 7\% $n$-propylbenzene.

\section{Model description}

\subsection{Kerosene injection and spray break-up model}

The CFD code Fluent is used in the study, a "Plain Orifice Atomiser" (POA) model is used to model the high-speed liquid injection into a gaseous atmosphere. The model is suitable to simulate

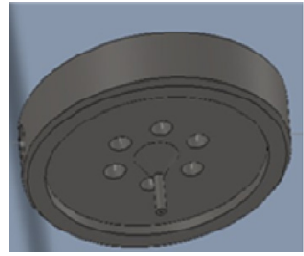

(a) upper part

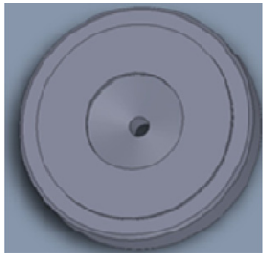

(b) lower part
Fig. 3. View on the coaxial injection head.

kerosene injector with a long and thin orifice, and the orifice connects a high pressure reservoir of kerosene within the injector to the high-pressure steam of the decomposed hydrogen peroxide in the combustion chamber (see Fig. 3). Using the POA model enables the injection and subsequent atomization of the kerosene jet to be modeled without the need to create complicated mesh geometry. The main parameters used in the case modeled here are as follows: inner diameter of kerosene tube: $0.7 \mathrm{~mm}$; tube length: $5 \mathrm{~mm}$; mass-flow rate of kerosene: $7 \mathrm{~g} / \mathrm{s}$.

The "wave" model in Fluent is used to model kerosene spray break-up. The wave model of Reitz [6] considers that the break-up of an injected liquid is induced by the relative velocity between the liquid and gas phases. Once the spray breaks up into droplets, the penetration of the spray depends mainly on the aerodynamic drag of the droplets. This model is chosen for this study. To take into account the turbulence effects, the realizable $k-\varepsilon$ turbulence model is used.

\subsection{Eulerian-Langrangian Discrete Phase Model (DPM)}

In the study, Eulerian-Langrangian Discrete Phase Model (DPM) is used, the flow of discrete fluid droplets is introduced to treat with an Eulerian description and the other with a Lagrangian approach. At the interface between the phases, the partial pressure of the vapor is considered equal to the saturated vapor pressure calculated at the liquid temperature. The rate of vaporization is governed by the gradient diffusion.

\subsection{Thermodynamic model}

The equation of state employed in the present study is the Peng-Robinson (PR) cubic equation, which is used in the Lagrangian/Eulerian description:

$P=\frac{R T}{V-b}-\frac{a}{V^{2}+2 b V-b^{2}}$

where $R$ is the universal gas constant and $V$ is the molar volume. Terms $a$ and $b$ are coefficients that account for attraction and repulsion effect among molecules. Details of the application of these equations can be found in Ref. [7].

\subsection{Combustion model}

The combustion in liquid rocket propulsion typically occurs in the flamelet regime of turbulent combustion [8,9], which enables the use of the flamelet model for turbulent spray diffusion flames. Thus, the combustion is modeled by a Flamelet approach including non-equilibrium effects and a PDF-treatment to take into account turbulent combustion. In the flamelet model used in the non-premixed combustion model, the turbulent diffusion flame is considered as an ensemble of laminar flamelets, and chemical reactions and heat transfer occur in a thin layer. The thermochemistry calculations are preprocessed and then tabulated for lookup in the CFD code. Interaction of turbulence and chemistry is 
Table 1

Compositions of China No. 3 aviation kerosene.

\begin{tabular}{|c|c|c|c|c|c|c|}
\hline \multicolumn{7}{|c|}{ Composition (mass basis) of China no. 3 aviation kerosene (\%) } \\
\hline \multicolumn{4}{|c|}{ Saturated hydrocarbons } & \multicolumn{3}{|c|}{ Aromatic hydrocarbons } \\
\hline \multirow{2}{*}{ Alkanes } & \multicolumn{3}{|l|}{ Naphthenes } & \multirow[t]{2}{*}{ Alkyl benzenes } & \multirow[t]{2}{*}{ Indan and tetralin } & \multirow[t]{2}{*}{ Naphthalene and derivatives } \\
\hline & Monocyclic & Bicyclic & Tricyclic & & & \\
\hline 52.2 & 33.8 & 6.0 & 0.1 & 5.1 & 1.3 & 1.5 \\
\hline \multicolumn{7}{|c|}{ Surrogate compositions (mole fraction) for China no. 3 aviation kerosene (\%) } \\
\hline \multicolumn{3}{|c|}{$n$-decane $\left(\mathrm{C}_{10} \mathrm{H}_{22}\right)$} & \multicolumn{3}{|c|}{ n-propylbenzene $\left(\mathrm{C}_{9} \mathrm{H}_{12}\right)$} & 1,3,5-trimethylcyclohexane $\left(\mathrm{C}_{9} \mathrm{H}_{18}\right)$ \\
\hline \multicolumn{3}{|l|}{49} & \multicolumn{3}{|l|}{7} & 44 \\
\hline
\end{tabular}

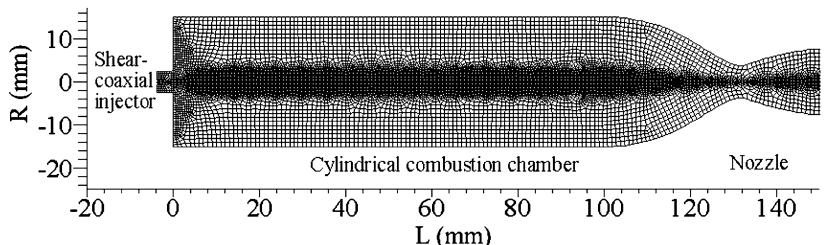

(a) Computing domain of combustion



(b) Computing domain of exhaust plume

Fig. 4. Scheme grids of computing domain.

accounted for with an assumed-shape Probability Density Function (PDF). A high-temperature combustion skeletal mechanism of kerosene containing 79 species and 330 reactions is used in the thermochemistry calculations, and the mechanism was described and validated in Ref. [10].

\subsection{Radiative heat transfer model}

The Discrete Ordinates (DO) radiation model with a variable absorption coefficient and the weighted-sum-of-gray-gases model (WSGGM) are employed in the study.

\subsection{Mesh generation and numerical schemes}

In the simulation of the experimental combustion chamber and exhaust plume, the scheme grids of computing domain are shown in Fig. 4. The domain is modeled by a combination of (hexahedral) individually discretized numerical sub-grids, and the grids are refined in the zones of spray, atomization, vaporization and central exhaust plume. Adequate grid independence is satisfied with a mesh of 406609 cells, and the minimum and maximum volumes are $6.18 \times 10^{-13}$ and $9.87 \times 10^{-7} \mathrm{~m}^{3}$, respectively. The simulation time required for a case is about 6 h by using $8 \mathrm{CPU}$ cores.

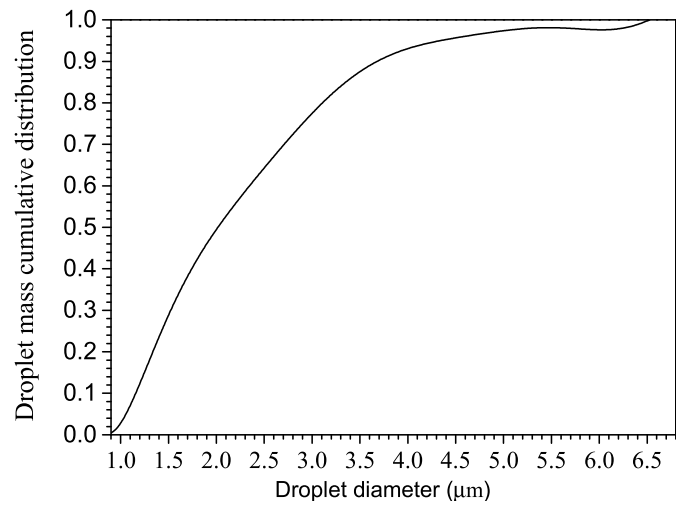

Fig. 5. Droplet diameter distribution at the chamber inlet.

\section{Results and discussion}

\subsection{Kerosene atomization and evaporation}

In the rocket combustion chamber, although kerosene can be autoignited by the high-temperature oxidizer stream, the relative small amount of fuel is difficult to completely mix with the oxidizer where the oxidizer-to-fuel $(\mathrm{O} / \mathrm{F})$ mass ratio is about 7 . Thus, the ignition delay of kerosene mainly depends on the physical delay (atomization, vaporization and mixing).

The atomization characteristics of oxidizer gas/kerosene shear coaxial injection are influenced by the following the two parameters: Reynold's number $(R e)$ of liquid jet and aerodynamic Weber number (We) of the gas-liquid flow. In the jet simulation, the values of Re and We are 8340 and 414, respectively. Fig. 5 shows the atomization characteristics of kerosene/oxidizer gas shear coaxial injection. The aerodynamic interactions between the liquid kerosene surface and gaseous oxidizer bring about the instability and disintegration of the liquid into small drops, the high momentum of the gaseous oxidizer stream rapidly atomizes the liquid fuel. The droplet diameter distribution at the location of chamber inlet is shown in Fig. 5, and the maximal diameter is about $6 \mu \mathrm{m}$.

Fig. 6 depicts kerosene droplet spray domain and evaporation rate contour. The spray spread angle is $13^{\circ}$ (see Fig. 6a), the droplets almost disappear at the axial location of $20 \mathrm{~mm}$, the lasting time of atomization is about $1 \mathrm{~ms}$. As known from Fig. 6, the atomization and evaporation occur and complete simultaneously, and the maximal vaporization rate reaches $1.5 \times 10^{-6} \mathrm{~kg} / \mathrm{s}$.

In the study, the time evolution of the species mass fractions and the temperature are modeled using the unsteady flamelet equations [11]. For the two streams of oxidizer (decomposed peroxide hydrogen gas) and fuel (kerosene vapor), one with fuel at a mass fraction of $Y_{\mathrm{F}, 1}$ and one with oxidizer at a mass fraction of $Y_{\mathrm{O}, 1}$, the mixture fraction, $Z$, is defined by

$Z=\frac{a Y_{\mathrm{F}}-Y_{\mathrm{O}}+Y_{\mathrm{O}, 2}}{a Y_{\mathrm{F}, 1}+Y_{\mathrm{O}, 2}}$

where $a$ is the stoichiometric mass ratio. 


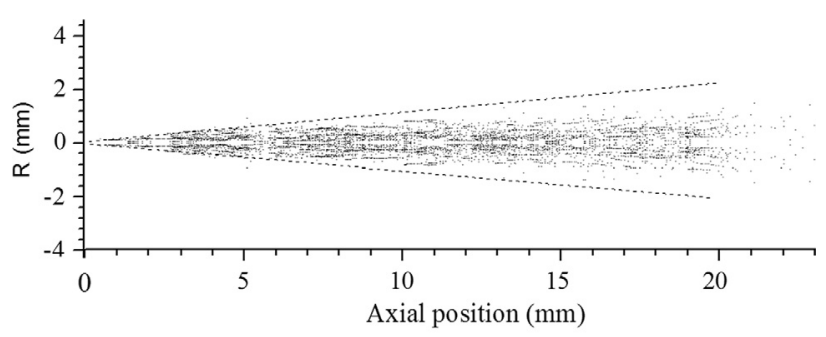

(a) Drop distribution domain

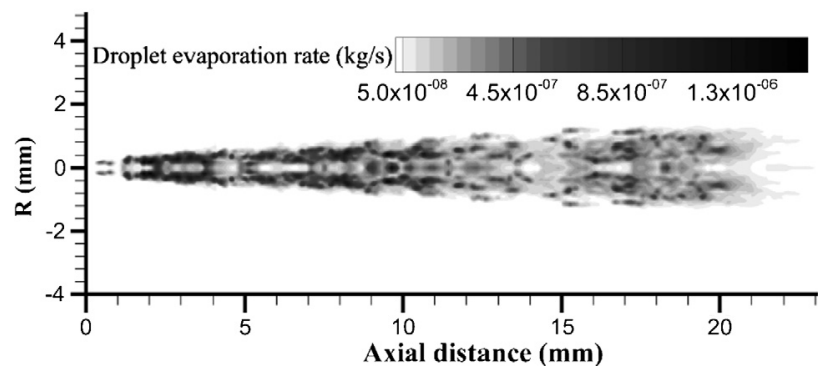

(b) Drop kerosene vaporization rate

Fig. 6. Kerosene droplet spray domain and evaporation rate contour.

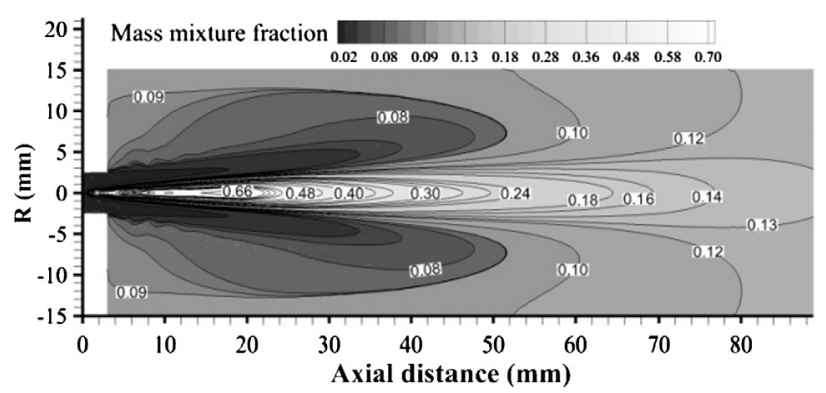

(a) Mixture fraction contour

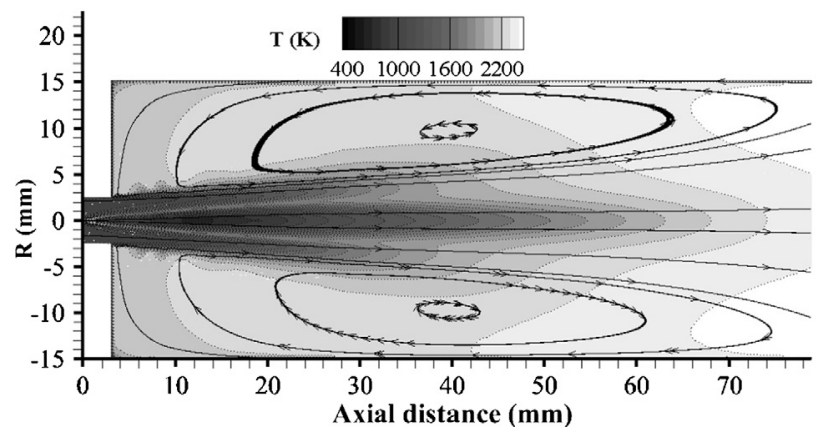

(b) Temperature contour and streamline

Fig. 7. Mixing characteristics of kerosene/decomposed peroxide hydrogen in combustion chamber.

Fig. 7 depicts the mixing characteristics of kerosene/decomposed peroxide hydrogen in combustion chamber. In the front of combustion chamber, there is a core zone of evaporation where kerosene mixture fraction can reach 0.66 , and it is a rich-fuel zone, which corresponds to the atomization and evaporation zone in Fig. 6. In the surround core zone, there is turbulent recirculating flow, and a large amount of high-temperature gas is entrained into the core zone, which enhances the heat and mass transfer and strengthens the turbulent combustion.

\subsection{Combustion chemical analysis}

Although the processes of atomization and evaporation mainly occur at the front zone of chamber, the physical process is ac-

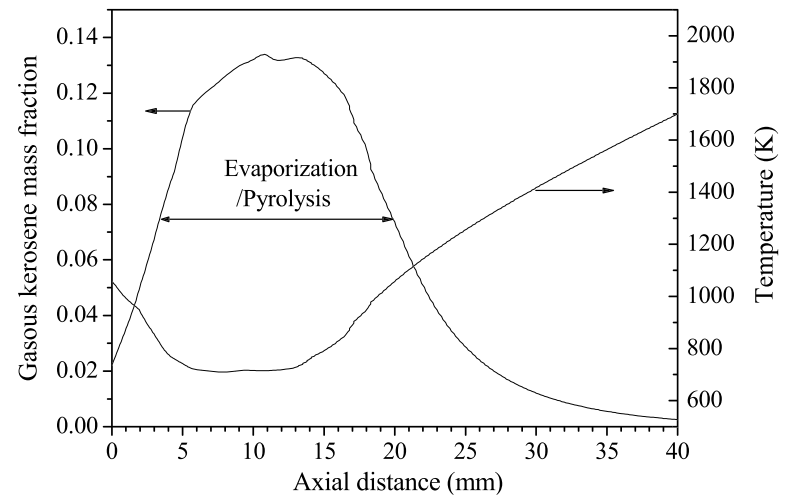

(a)

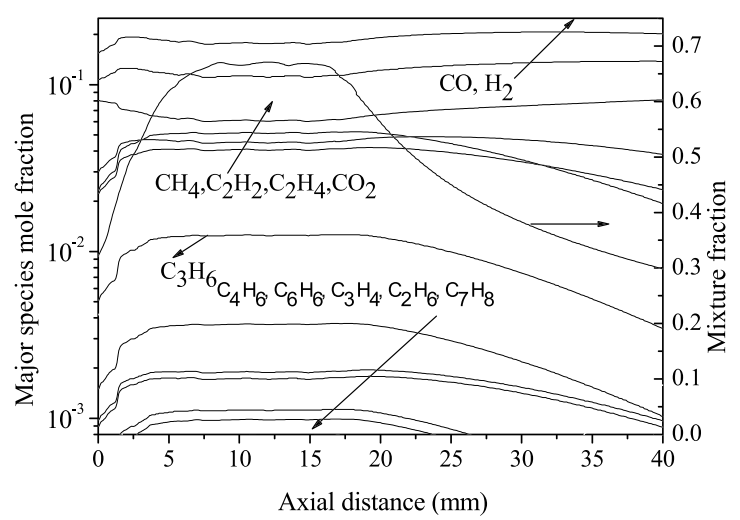

(b)

Fig. 8. The profiles of temperature, species concentrations and mixture fraction at axial centerline of the front zone of combustion chamber.

companied by combustion chemical process, such as ignition, fuel pyrolysis, etc. Fig. 8 presents profiles of temperature, species concentrations and mass mixture fraction at the front zone of combustion chamber. Due to the high temperature of oxidizer stream and the great injection momentum ratio of oxidizer to fuel (above 10), once propellants inject, the heat and mass transfer rapidly, and the kerosene droplets sharply preheat and evaporate. As known from Fig. $8 \mathrm{~b}$, the mixture rapidly increases to 0.33 at chamber inlet, the temperature drastically reaches $1197 \mathrm{~K}$ at the axial location of 0 $\mathrm{mm}$ (namely, injector outlet), and then the temperature decreases and fuel vapor concentration (or mixture fraction) increases in the endothermic process of evaporation and pyrolysis.

The process of kerosene pyrolysis can be considered to complete at the axial location of $20 \mathrm{~mm}$. During the rapid hightemperature pyrolysis, kerosene is decomposed into small molecular hydrocarbon gas (such as $\mathrm{CH}_{4}, \mathrm{C}_{2} \mathrm{H}_{2}$, and $\mathrm{C}_{2} \mathrm{H}_{4}$ ) and $\mathrm{H}_{2}$ (see Fig. 8b). A large amount of carbon monoxide (CO) is produced during the partial combustion, the exothermic oxidation reaction becomes dominant behind the location of $15 \mathrm{~mm}$ along the axial centerline, the temperature begins to increase (see Fig. 8a), and mixture fraction begins to decrease (see Fig. 8b).

Kerosene is a mixture of large hydrocarbon molecules $\left(\mathrm{C}_{10} \mathrm{H}_{22}\right.$, $\mathrm{C}_{9} \mathrm{H}_{18}$ and $\mathrm{C}_{9} \mathrm{H}_{12}$ ), the combustion reaction paths are complex in the rocket combustion chamber with high-pressure, high-speed and high-temperature flow environment. The initial excitation of kerosene reactions is a crucial link, which is depicted in Fig. 9. The hydrogen abstraction reactions of the hydroxyl radical and $\mathrm{H}$ free radical with $\mathrm{C}_{10} \mathrm{H}_{22}, \mathrm{C}_{9} \mathrm{H}_{18}$ and $\mathrm{C}_{9} \mathrm{H}_{12}$ are the dominant reactions involving the direct decomposition. The major intermediates of $\mathrm{H}$-abstraction reactions of $n$-decane $\left(\mathrm{NC}_{10} \mathrm{H}_{22}\right)$, $n$-propylcyclohexane (CYC9H18) and n-propylbenzene $\left(\mathrm{PHC}_{3} \mathrm{H}_{7}\right)$ are 3-decyl $\left(\mathrm{CC}_{10} \mathrm{H}_{21}\right)$, 4-decyl $\left(\mathrm{DC}_{10} \mathrm{H}_{21}\right)$ and 5-decyl $\left(\mathrm{EC}_{10} \mathrm{H}_{21}\right)$, 


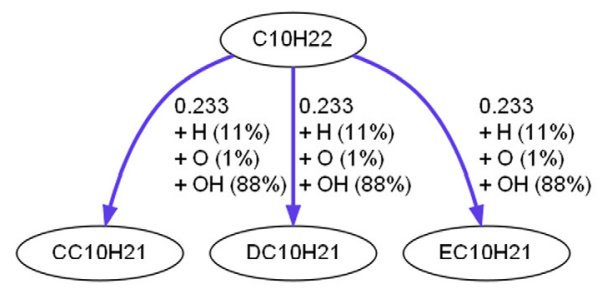

(a)

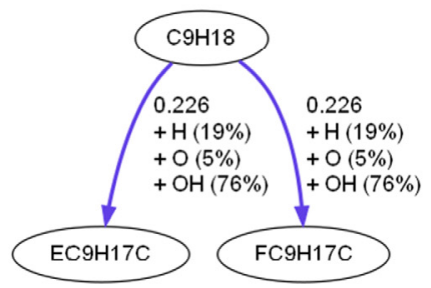

(b)

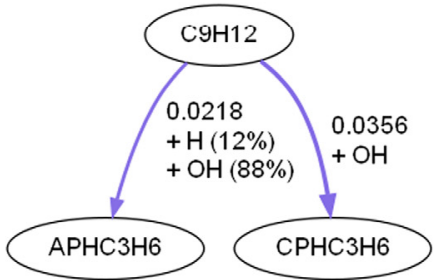

(c)

Fig. 9. The complex reaction paths of kerosene pyrolysis (at axial distance $13.4 \mathrm{~mm}, 726 \mathrm{~K}$ ).

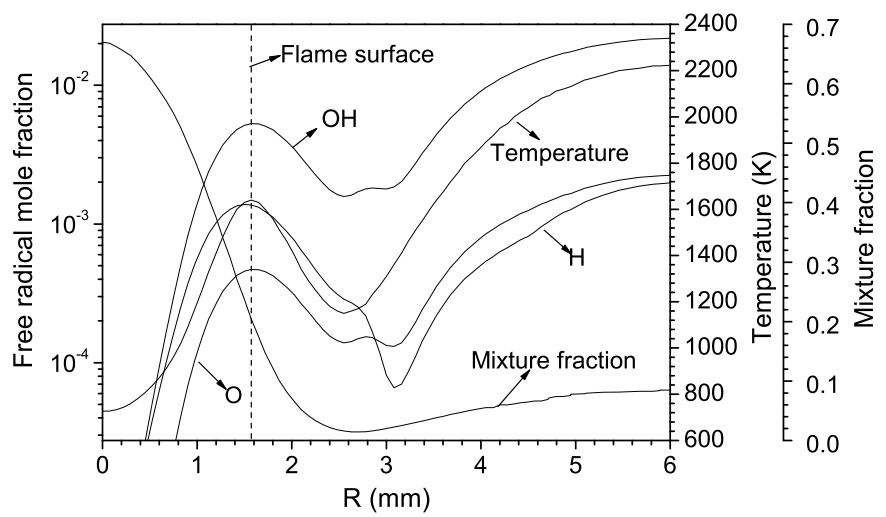

Fig. 10. The profiles of free radical $\mathrm{OH} / \mathrm{O} / \mathrm{H}$ along radius (at axial distance $13 \mathrm{~mm}$ ).

cyclohexyl-propyles $\left(\mathrm{EC}_{9} \mathrm{H}_{17} \mathrm{C}, \mathrm{FC}_{9} \mathrm{H}_{17} \mathrm{C}\right), \mathrm{APHC}_{3} \mathrm{H}_{6}$ and $\mathrm{CPHC}_{3} \mathrm{H}_{6}$, and the reaction channels are as follows:

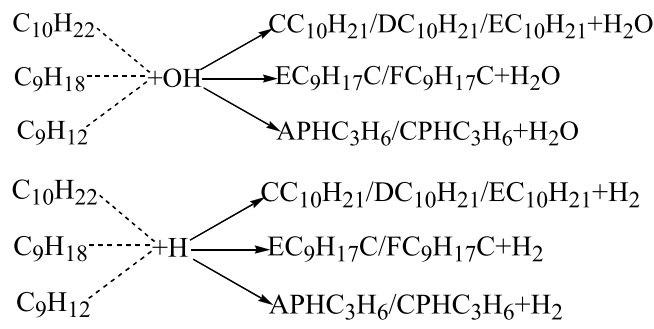

As known from above analysis, $\mathrm{H}$ and $\mathrm{OH}$ free radicals are very important, but the temperature is only about $700 \sim 800 \mathrm{~K}$ in the pyrolysis zone (see Fig. 8a), the formation of the two free radicals is impossible in the zone. However, there is a sheet flame surface around the evaporation/pyrolysis zone, small amount of fuel vapor combusts with high-speed injection flow of high-temperature oxidizer stream, where large amount of $\mathrm{OH}$ free radical is formed. In order to further analyze the formation of $\mathrm{O} / \mathrm{OH} / \mathrm{H}$ free radicals which are crucial to kerosene pyrolysis, the profiles of these free radicals along radius are shows in Fig. 10.

A large amount of $\mathrm{H} / \mathrm{O} / \mathrm{OH}$ is formed at $R=1.6 \mathrm{~mm}$ where is the location of sheet flame surface shown in Fig. 10, the temperature and mixture fraction reaches $1619 \mathrm{~K}$ and 0.2 , respectively (see Fig. 10). Based on the location of high-concentration $\mathrm{OH}$ formation, the flame surface is defined. The low-temperature inner side and low-mixture outside of the flame sheet are not suitable for combustion, and thus these free radicals only form in the flame sheet. Fig. 11 depicts the formation paths of free radicals of $\mathrm{O} / \mathrm{OH} / \mathrm{H}$, and the dominant reaction paths are as follows:

$\mathrm{H}+\mathrm{H}_{2} \mathrm{O} \rightarrow \mathrm{OH}+\mathrm{H}_{2}$

$\mathrm{H}+\mathrm{O}_{2} \rightarrow \mathrm{OH}+\mathrm{O}$

$\mathrm{H}_{2}+\mathrm{OH} \rightarrow \mathrm{H}+\mathrm{H}_{2} \mathrm{O}$

$\mathrm{H}_{2}+\mathrm{O} \rightarrow \mathrm{H}+\mathrm{OH}$
$\mathrm{O}_{2}+\mathrm{H} \rightarrow \mathrm{O}+\mathrm{OH}$

As known from (R3)-(R7), the above reactions of these free radicals are interactive. In order to make these free radicals diffuse into the fuel pyrolysis zone, the turbulent flow mass transfer is very important for the mixing between pyrolysis zone and the flame sheet in the high-speed turbulent flow in the front zone of chamber. The mixture fraction rapidly decreases from 0.68 to 0.05 in the radius range from 0 to $2.6 \mathrm{~mm}$, which means the intensive mixing occurs in the region. The recirculated flow eddies in Fig. 7 enhance the diffusion of these free radicals $(\mathrm{O}, \mathrm{OH}$ and $\mathrm{H})$ into the pyrolysis region, the mixing of fuel and oxidizer is strengthened, which is conducive to combustion.

Fig. 12 shows the major species profiles in the rear zone of combustion chamber and nozzle region, it indicates that small hydrocarbon molecules rapidly combust and reach equilibrium state at the end of the combustion chamber, where the maximal temperature reaches $2458 \mathrm{~K}$.

In the nozzle region, although the temperature decreases from 2458 to $1350 \mathrm{~K}$ due to the flow expansion, the flow is supersonic, gas composition at each stage of expansion is not in equilibrium $(\mathrm{Da}<<1)$, temperature falls so rapidly that the reaction time may be insufficient time for dissociated products to recombine during the expansion, the species concentrations keep constant without chemical change at all times in the nozzle flow process, and thus it is called frozen flow rather than equilibrium flow.

Since the combustion temperature reaches above $2000 \mathrm{~K}$, the vibrational energy of gas molecules becomes excited, some gas molecules begin to dissociate. Rocket combustion chamber temperatures are so high that typically substantial portion of combustion products are dissociated. When temperature is greater than $2000 \mathrm{~K}, \mathrm{O}_{2}$ and $\mathrm{H}_{2}$ begin to dissociate $\left(\mathrm{O}_{2} \rightarrow 2 \mathrm{O}, \mathrm{H}_{2} \rightarrow 2 \mathrm{H}\right)$; the dissociation temperature of $\mathrm{CO}_{2}$ and $\mathrm{H}_{2} \mathrm{O}$ is $2000 \mathrm{~K}\left(\mathrm{CO}_{2} \rightarrow \mathrm{CO}+\mathrm{O}\right.$, $\mathrm{H}_{2} \mathrm{O} \rightarrow \mathrm{OH}+\mathrm{H}$ ); the dissociation extent depends on temperature. As known from Fig. 12, when temperature reaches above $2000 \mathrm{~K}$, free radicals of $\mathrm{O}, \mathrm{H}$ and $\mathrm{OH}$ noticeably increase, and $\mathrm{CO}$ and $\mathrm{CO}_{2}$ reach equilibrium. Since the residence time is very short in the nozzle, the time is not enough for free radical association, and these free radicals keep constant to issue out from nozzle. Since the dissociation of molecules consume energy, it reduces the combustion efficiency.

\subsection{Plume flow analysis}

Rocket plume refers to the exhaust gases released from nozzle outlet. In the experiment, a series of disks can be seen in the exhaust plume due to high temperature radiation (see Fig. 13a), the yellow color shades of image are Mach disks, and the visible Mach disks are evenly spaced in the plume.

In the plume, the variations of pressure, temperature and Mach number of plume are very complex, the profiles of static pressure, temperature and Mach number of plume along the axial centerline are provided in Fig. 14. In the study, since the experiment is ground test where is at atmospheric pressure $\left(1.036 \times 10^{5} \mathrm{~Pa}\right)$, 


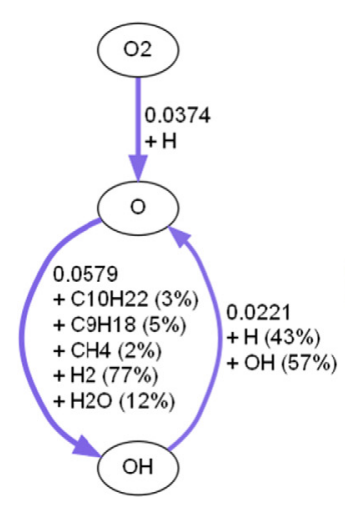

(a)

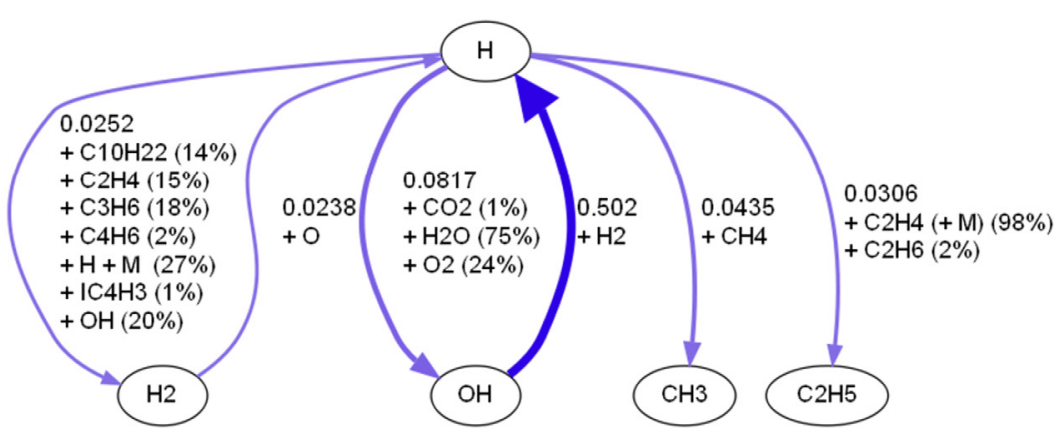

(b)

Fig. 11. The formation paths of free radical $\mathrm{OH} / \mathrm{O}$ (at radial distance $1.6 \mathrm{~mm}, 1640 \mathrm{~K}$ ).

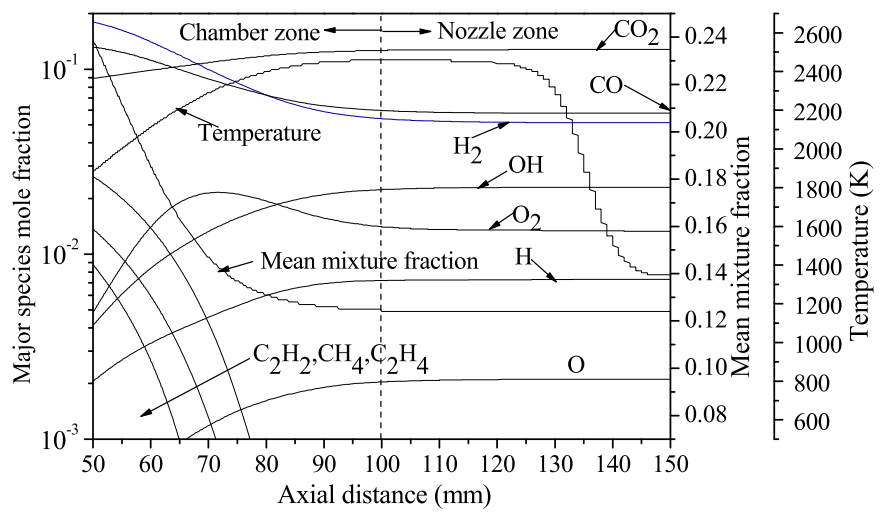

Fig. 12. The profiles of temperature, species concentrations and mixture fraction at the back part centerline of chamber.

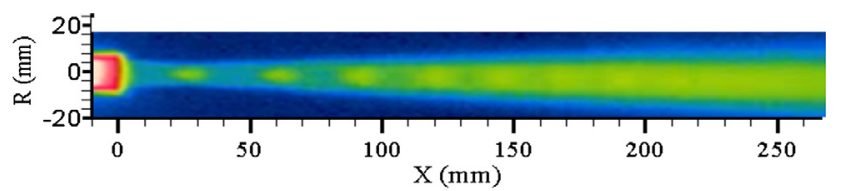

(a) Plume image of experiment

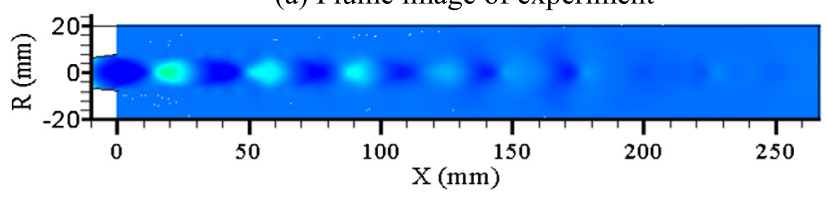

(b) Static pressure contour of simulation in the plume

Fig. 13. The characteristics of exhaust plume in the experiment and simulation in the plume. (For interpretation of the references to color in this figure, the reader is referred to the web version of this article.)

the exit pressure of the exhaust plume is $5.570 \times 10^{4} \mathrm{~Pa}$ at nozzle outlet where the axial distance of plume is equal to $0 \mathrm{~mm}$ (see Fig. 14). Since the outlet pressure is lower than the external atmospheric pressure, this situation is referred to as overexpansion. When a flow is overexpanded, the lower gas pressure within the exhaust compared to that of the external atmosphere causes the exhaust to be compressed or squeezed inward. However, the flow may be compressed too much so that its pressure exceeds the atmospheric pressure. As a result, the flow now expands back outward to reduce the pressure again. This process may also expand too far causing the internal pressure to again drop lower than the ambient pressure. In other words, the flow will repeatedly contract and expand while gradually equalizing the pressure difference between the exhaust and the atmosphere, and simultaneously it is accompanied by the increase and decrease of temper-

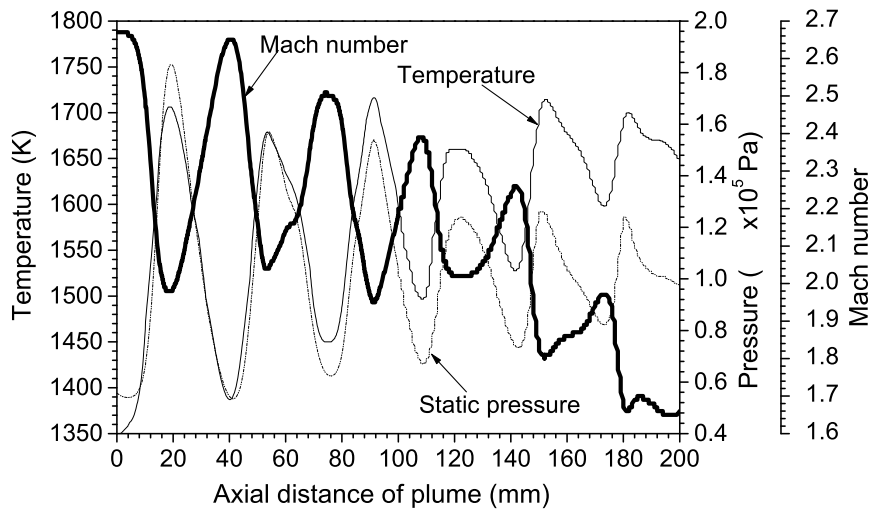

Fig. 14. The profiles of static pressure, temperature and Mach number of exhaust plume along the axial centerline.

ature (see Fig. 14). The static pressure contour of simulation in the plume is shown in Fig. 13b, the contraction of plume flow results in the increase of pressure and temperature and the decrease of Mach number or velocity (see Fig. 14), the location of high static pressure is that of high temperature, and thus the distributions of visible Mach disks (see Fig. 13a) and high static pressure (see Fig. 13b) are similar. In Fig. 14, these peak values evenly distribute along plume axis almost, and the interval distances of these peak values are about $32 \mathrm{~mm}$ along the centerline of axis.

\section{Conclusions}

The complex $\mathrm{H}_{2} \mathrm{O}_{2}$ / kerosene turbulent flow and combustion chemical reaction are modeled. During the kerosene injection, the spray angle is $13^{\circ}$, the lasting time of atomization is about $1 \mathrm{~ms}$, and the maximal vaporization rate reaches $1.5 \times 10^{-6} \mathrm{~kg} / \mathrm{s}$. The combustion chamber can be divided into the following three zones: rapid high-temperature pyrolysis zone, oxidization zone and equilibrium flow zone.

The initial excitation of kerosene reactions is crucial link, and the recirculated flow eddies enhance the free radicals of $\mathrm{O} / \mathrm{OH} / \mathrm{H}$ to diffuse into the pyrolysis region. Small hydrocarbon molecules of the pyrolysis products of rapidly combust and reach equilibrium state at the end of the combustion chamber.

In the exhaust plume, the flow repeatedly contracts and expands while gradually equalizing the pressure difference between the exhaust and the atmosphere, and simultaneously it is accompanied by the increase and decrease of temperature. These peak values of static pressure, temperature, Mach number almost evenly distribute along plume axis, and the interval distances are about $32 \mathrm{~mm}$ along the centerline of axis. 


\section{Conflict of interest statement}

None declared.

\section{Acknowledgements}

Financial support by National Natural Science Foundation of China (Nos. 51376189, 91530112) is acknowledged.

\section{References}

[1] T. Zhang, Y. Cong, T. Li, J. Sun, X. Wang, L. Ma, Propulsive performance of hypergolic $\mathrm{H}_{2} \mathrm{O}_{2}$ /kerosene bipropellant, J. Propuls. Power 20 (1) (2004) 83-86.

[2] D. Schlotz, E. Gutheil, Modeling of laminar mono- and bidisperse liquid oxygen/hydrogen spray flames in the counterflow configuration, Combust. Sci. Technol. 158 (1) (2000) 195-210.

[3] X. Fan, F.Q. Zhong, G. Yu, J.G. Li, C.J. Sung, Catalytic cracking of China No. 3 aviation kerosene under supercritical conditions, in: 44th AIAA/ASME/SAE/ASEE Joint Propulsion Conference \& Exhibit, 21-23 July 2008, Hartford, CT, USA, 2008, AIAA-2008-5130.
[4] P. Dagaut, On the kinetics of hydrocarbons oxidation from natural gas to kerosene and diesel fuel, Phys. Chem. Chem. Phys. 4 (11) (2002) 2079-2094.

[5] X. Fan, G. Yu, J. Li, X. Zhang, C.J. Sung, Investigation of vaporized kerosene injection and combustion in a supersonic model combustor, J. Propuls. Power 22 (1) (2006) 103-110

[6] P.K. Senecal, D.P. Schmidt, I. Nouar, C.J. Rutland, R.D. Reitz, M.L. Corradini, Modeling high-speed viscous liquid sheet atomization, Int. J. Multiph. Flow 25 (6) (1999) 1073-1097.

[7] J.O. Valderrama, The state of the cubic equations of state, Ind. Eng. Chem. Res. 42 (8) (2003) 1603-1618.

[8] H.W. Ge, E. Gutheil, Simulation of a turbulent spray flame using coupled PDF gas phase and spray flamelet modeling, Combust. Flame 153 (1) (2008) $173-185$.

[9] A. Coclite, L. Cutrone, P. De Palma, Numerical investigation of highpressure combustion in rocket engines using flamelet/progress-variable models, arXiv:1502.05360, 2014.

[10] J.Q. Xu, J.J. Guo, A.K. Liu, Construction of autoignition mechanisms for the combustion of RP-3 surrogate fuel and kinetics simulation, Acta Physico-Chimica Sinica 31 (4) (2015) 643-652.

[11] W.L. Chan, H. Kolla, J.H. Chen, Assessment of model assumptions and budget terms of the unsteady flamelet equations for a turbulent reacting jet-in-crossflow, Combust. Flame 161 (10) (2014) 2601-2613. 